\title{
Criteria Regarding Software and Data for a Successful Implementation of GI(S) in the Geography Classroom
}

\author{
Selected Results from Group Discussions \\ with Geography Teachers in Germany
}

\author{
Steffen HÖHNLE ${ }^{1}$, Rainer MEHREN ${ }^{1}$ and Jan Christoph SCHUBERT ${ }^{2}$ \\ ${ }^{1}$ FAU Erlangen-Nuremberg, Nuremberg / Germany·steffen.hoehnle@fau.de \\ ${ }^{2}$ WWU Muenster / Germany
}

This contribution was double-blind reviewed as full paper.

\begin{abstract}
Given the low implementation of GI(S) in the geography classroom at German schools, it was examined which support geography teachers need from their perspective, in order to implement $\mathrm{GI}(\mathrm{S})$ in their teaching.

The results illustrate that there are eight main criteria which are important for the implementation of GI(S) from the teachers' perspective: adequate teaching examples, integration of $\mathrm{GI}(\mathrm{S})$ in teacher training at university, sustainable further training activities for teachers, didactical conditions, GI(S)-promoting conditions at the school, access and availability of geodata, adequate software solutions, and cooperation and exchange of the participating GI(S) actors. Two main criteria and their sub-criteria are discussed more deeply in this paper: software solutions and geodata availability.
\end{abstract}

\section{Presentation of the Problem}

In German as well as in international literature on the subject, the potential of GI(S) for geographic education has been widely described (see BAKER 2002, FAVIER \& VAN DER SCHEE 2009a, 2009b, VOGLER et al. 2010, and others). There is a broad consensus in scientific discourse on the subject that GI applications offer great opportunities for learning, for example, to gain geographical knowledge or for methodical approaches like inquirybased learning - or simply just to enhance the reputation of the subject. This is also true for teachers in Germany: They see great potential in the implementation of GI as well (see SCHUBERT et al. 2012). However, implementation of GI(S) in geography classrooms in Germany is still really low (see HöHNLE et al. 2010), which leads to the question of why this is the case, and what can be done to change it. This paper will address criteria from the teachers' perspective, to change this situation with a focus on the requirements for software and data for a better implementation of GI in the geography classroom. 


\section{Research Design and Methodical Proceeding}

As already mentioned, in the framework of earlier research projects it was found that the implementation of GI in German geography classrooms is quite low in spite of teachers seeing large potential in GI (see HÖHNLE et al. 2011, SCHUBERT et al. 2012). However, they also see big constraints in working with GI together with their students. These results were presented to teachers during group discussions which aimed at addressing the current status and problems constructively, and developing criteria for better implementation of GI in due consideration of the perception of the actors who actually have a key role in the implementation process (ZEITLER et al. 2012, 23ff). Thus, six group discussions (BOHNSACK 2004) were being led, five of which included homogenous groups, one a quite heterogenous group (1. Students of geographic education, 2. Students in teacher training in geography (German expression: Studienreferendare), 3. GI inexperienced teachers, 4. GI experienced teachers, 5. GI trainers, 6. heterogenous group of inexperienced teachers, experienced teachers and students), each including four to six participants.

The group discussions were performed during teacher training activities or the participants were invited to meet at the university building. The participants were confronted with the results of an earlier study about barriers for the implementation of GI (HÖHNLE et al. 2011) as a trigger for discussion. During these discussions the groups developed ideas from their perspective about how to overcome the existing barriers and improve implementation. The group discussions were analyzed using content analysis methodology (MAYRING 2000). The analysis delivered several criteria to consider when aiming at a better implementation of GI in the geography classroom.

The audio recordings of the group discussions were transcribed first (KowAL \& O'CONNELL 2004), which was followed by an editing process in order to obtain a revised version of the transcript for a better accessibility of the material. In due consideration of the research question, categories were determined, as well as respective levels of abstraction. After that, the inductive categories were formulated step by step out of the material, with the goal of subsuming the old categories or formulating new categories which are more suitable. The further steps included a revision of the categories, finalizing text work and the interpretation of the results. This process was accompanied by a formative and a summative check of reliability (see Fig. 1).

The software MAXQDA was used for coding the material in a computer aided manner (BOS \& TARNAI 1999), as well as for the development of categories. This was done independently by two researchers, the results were compared afterwards and the intercoder reliability was computed in order to guarantee the quality of the analysis process. For this purpose a procedure was used which examines the congruousness of the developed codings on a percentage basis. The computation of intercoder reliability (congruous codings of different coders) yielded high values of $\mathrm{R} \geq .76$ for the particular codes, the mean value for congruous codings was .83. For the criterion ,Software' the intercoder reliability was .79, for the criterion ,Data' it was .81, so we can say that coding objectivity was quite high. Regarding time-displaced reanalysis performed by the first coder of the material (= intracoder reliability) the values were higher than $\mathrm{R} \geq .82$ for all of the codes, the mean value for congruous codings of all of the codes was .88 . 


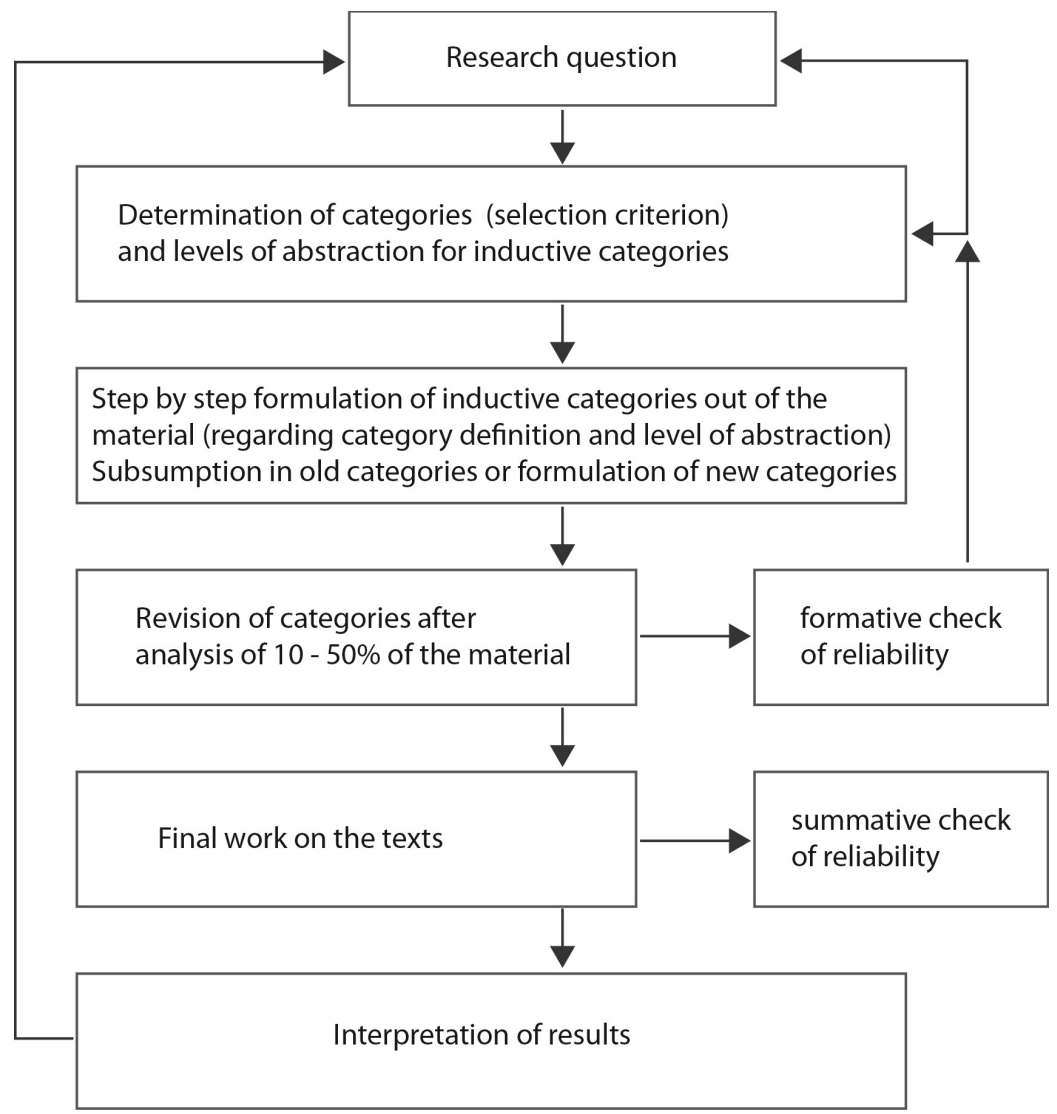

Fig. 1: Step model of inductive category development (adapted from MAYRING 2000)

As a last step, all the material coded within one category was summarized conducting a summarizing content analysis (MAYRING 2004). The result is an overview over generalized criteria for a successful implementation of GI(S) from the perspective of geography teachers. These criteria were supplemented with further theoretical and empirical findings from scientific literature in the field.

The quality of the methodical proceeding can be judged based on a well-reasoned, transparent and exactly documented procedure. A rule-governed, stepwise and methodically controlled procedure not only aimed at quality assurance but also at intersubjective inferability through independent analysis, reciprocal control by different analyzing researchers, and discussions of the steps of interpretation within a workgroup. 


\section{Results - Criteria for Software and Data}

From the group discussions with geography teachers, eight main criteria for successful implementation of GI(S) could be derived (see Fig. 2).

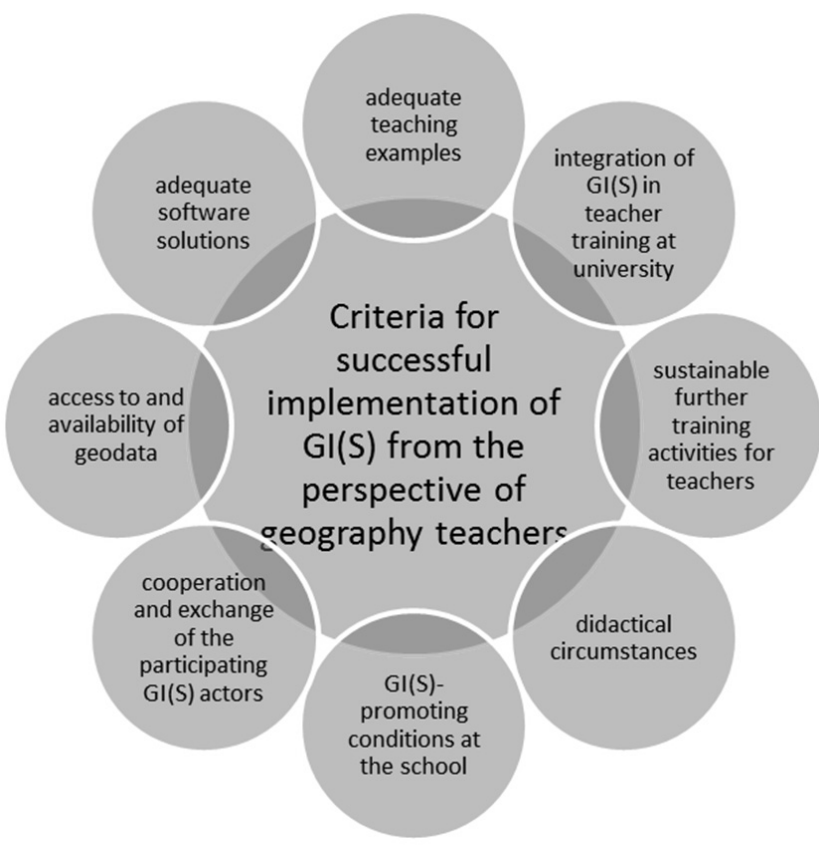

Fig. 2:

Criteria for successful implementation of GI(S) from the perspective of geography teachers in Germany

These main criteria can be differentiated into sub-criteria again, which we will do for two of the main criteria in this paper: adequate software solutions (see Fig. 3) and access to and availability of geodata (see Fig. 4).

These sub-criteria will be described shortly, and illustrated by quotes from the group discussions, which can be regarded as an example standing for various other quotes of similar nature.

\subsection{Software}

Regarding software solutions there are five sub-criteria which are essential for teachers considering the software adequate and suitable to their needs when teaching. 


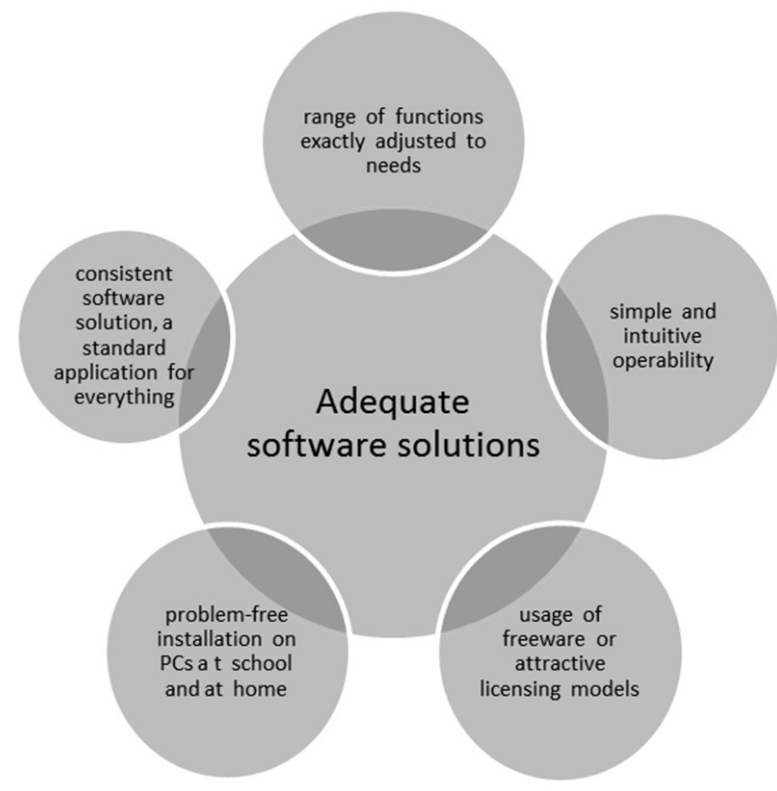

Fig. 3:

Overview of the sub-criteria regarding the main criterion "adequate software solutions"

\subsubsection{Range of functions exactly adjusted to needs}

From the point of view of the teachers, their needs in the classroom often differ from the needs of users in other contexts (also see discussions in literature on user- and task-centered applications). That is why they ask for a range of functions which really fit their needs. This means for example that there should not be too many functions making the application too complex for the classroom usage.

"I think that it is very important that there are WebGIS solutions which are fitting perfectly to the teaching arrangement. Which actually only offer the functions that I need for exactly this task. But I could also imagine that for advanced users add-on functionalities are needed. And then that there is an application with a configurable functionality for the user if you like."

\subsubsection{Simple and intuitive operability}

Teachers find it hard not only to get used to operating GI software themselves, but also to get their students used to the software. According to them this is a problem especially if one considers the low number of geography lessons taught, which already makes it hard to cope with other demands the teachers and the students have to fulfill. Thus simple and intuitively usable software is even more important for classroom usage than in other contexts where GI is used.

"Well I found the web-based GI-systems, hmm, yeah they were accessible more easily, simple! And this is a point for many teachers as well I think."

\subsubsection{Usage of freeware or attractive licensing models}

Teachers also feel that freeware or other attractive long-term licensing models are essential for implementing GI in the classroom. This stems from their experience that monetary 
resources are usually low at their schools. So they have to get back to solutions which are free of charge. The need for low-cost solutions becomes even more obvious if one considers a big fear teachers have when using licenses which are free of charge for a predetermined period of time only (some big players in GI software development have offered free usage of their products for a period of time in the past, but no free long-time usage of the products was guaranteed): Teachers do not really want to use this kind of software then. If they spend time getting to know the software and planning lessons with it accordingly, they want to have a long-time added value from their time investment. Thus, they refrain from using software solutions which are not free of charge permanently. A similar phenomenon can be observed regarding update procedures and changes in the screen design or functionality of the software: Teachers do not like updates which include this, they rather prefer the software environment they got used to. This gives them more security in the classroom and that things go as planned.

"And then one can just give them the application that is freeware. And I think this also helps somehow that it becomes a little more common for pupils then maybe because if you just have a few of them, then others might go along with them and I think this alone is worth it then."

"Well, we have already talked about the price of the software. Basically, it has to be affordable for a school!"

"And it has to be technically manageable, and it has to be effective for the teacher. So that the effort doesn't become sky high."

\subsubsection{Problem-free installation on PCs at schools and at home}

The limited time resources in the geography classroom lead to another need expressed by the teachers. It should be possible to install the software without any problems on PCs at school as well as on PCs at home. Thus, teachers can move time-consuming rather technical parts of the work process (getting adjusted to software etc.) to the workplace of the students at home. The work process in the classroom can then focus on the geographical questions much more without getting problems with the compliance of other demands they have to keep in mind. Installation on the PC at home is also needed for a thorough preparation of the lesson from the teacher's perspective.

"And I think you need the application on your computer at home as well. It is not enough if it is installed on the computers at school. So it is important that you have it at home in order to prepare your lessons and your teaching."

"Well, it has the advantage that every pupil can install it at home. So if I say: Guys, now you know this, download the application, install it and practise at home. I don't want to have the problem somehow you know - with licenses and so on."

\subsubsection{Consistent software solution, a standard application for everything}

An ideal situation which the teachers wish for would be a consistent software solution including a standard application for everything. This means a software product which they can use in various geographical contexts and in different grades. Thus, students get used to the software, and technical aspects become less and less important over time. This way the software really becomes just a tool for addressing geographical issues, unlike experiences they have made so far which included the consumption of too much classroom time for 
technical aspects or problems with new students in the class which have not worked with the software so far.

"It would be best of course if one could set a standard with just one application. Bavariawide. That then really when they go to other schools they can continue."

\subsection{Data}

The second main criterion which we will address is "availability of geodata". Regarding geodata six criteria have proved to be essential for the teachers.

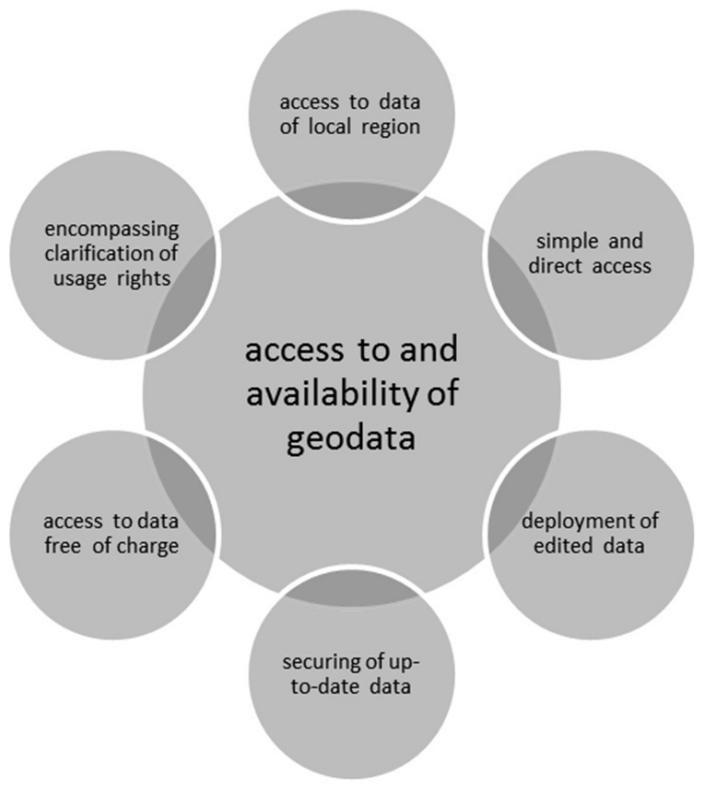

Fig. 4:

Overview of the sub-criteria regarding the main criterion "access to and availability of geodata"

\subsubsection{Access to data of local region}

Teachers want to work on geographic questions which have reference to the vicinity of the school and thus have relevance to the students. That is why they consider access to data of the local region as very important. This does not necessarily mean that large amounts of data have to be available to them. It is rather about pieces of information which are necessary for answering quite simple geographic questions.

„Now there are more and more municipalities and local administrations which upload their data to the web and which can be used."

Nevertheless there is the problem regarding data in all of that of course. For example I did something like that with my students. Socio-spatial distribution in city [...]. But you have to do missionary work first of course convincing the people at the administration office that they give you their data finally." 


\subsubsection{Simple and direct access}

Another important aspect for teachers is that they want to have simple and direct access to data. If they come up with an idea in their preparation of lessons maybe on the day before, they want to be able to get data quickly and easily. The same is true for cases when maybe an interesting geographic question arises in the classroom and they want to address this question using geodata.

„,Yeah, there you have missing datasets and things like that. It was too difficult or is too difficult to get data from your own municipality. You should just have that on the table! And this would have to be simple and without any problems. "

\subsubsection{Deployment of edited data}

It has also become obvious that the availability of edited data is essential for teachers. The background of this is that teachers do not have to go through every step of the analysis themselves or together with their class. Instead they can select relevant steps for their specific goal. Another aspect is that they can then focus on working on the "real" geographic part of GI usage, which has to be the promotion of geographic and spatial thinking without having to spend too much time on the technical aspects.

"But we have to end very often, we fail, because the data has to be edited. Some of us are able to do that, others are not. And this Is too much effort for the teachers. That should't be the case at school."

"And very important in this context is that the data is edited. And that you don't have to search for data for a long time."

\subsubsection{Securing of up-to-date data}

For the teacher, up-to-date data is really important. Up-to-dateness is one of the main advantages geography has in comparison to other subjects from their point of view. If teachers want to take advantage of that they need current data and can thus spark the involvement of their students. That is why they want to have guaranteed that the available data is not outdated, and that the latest data is always available for them. So they could answer recent geographic questions based on working with GI and come up with insights and solutions that actually matter.

„, There are some companies which are on the right track regarding this. Some webGIS tools are that advanced right now that one can say, well we have the maps in our atlas, but online we have digital maps which are much more up-to-date and which are refreshed regularly."

\subsubsection{Encompassing clarification of usage rights ${ }^{1}$}

Teachers are often somewhat puzzled with usage rights regarding data. They often feel insecure what they are allowed to do with it and if, for example, they can publish the students' results which are based on data they have received from another source. That is why they need support in this regard, since they often do not know the ropes of usage rights and thus do not use the data at all because they do not want to have any problems.

\footnotetext{
1 This criterion has been added based on the results of a performed preliminary study.
} 


\subsubsection{Access to data free of charge}

Financial resources are short in most of the schools, so most of the time teachers have to pay for additional material which they want to use in the classroom out of their own pockets. This is an unsatisfactory circumstance which teachers do not want to have to cope with in yet another field of innovation which they shall implement into their teaching. That is why it is important for them that access to data is free of charge.

„Whereas I would also say here that I find it downright pathetic how here in North-Rhine Westfalia the State Office for Statistics acts. You have to buy the data from them! In Bavaria for example the data for municipalities are uploaded to a server and the schools get access completely free of charge, for Bavaria. "

„Nothing is available free of charge, there are no workable datasets on the table. “

„Every lesson needs data and you have to get them from somewhere. And desktop solutions need either data delivered on CDs or data which you have produced yourself."

\section{Conclusion}

The implementation of GI into the geography classroom has proven to be a difficult endeavor. However, having a closer look at the steps which have to be taken from the teachers' perspective regarding software and data, these difficulties can be surmounted.

Regarding software, freeware, open-source or other solutions free of charge should be preferred. In addition, an active community of users which discuss problems online seems to be really important for the teachers. There are several software solutions available which fulfill these criteria (e. g. ArcGIS online, Spatial Commander, Quantum GIS). Usability studies in the school context (e. g. DÜREN \& BARTOSCHEK 2013) can be another key for successful implementation. Easy drag and drop-interfaces like several web-based services, e. g. ArcGIS online, can make it easier for teachers and their students to get into the application more quickly and thus be able to spend more of the valuable time in the classroom for the really important geographical issues.

For the conditions in Germany, cooperation between data producers like land surveying offices or other governmental agencies and the education authorities like local schoolboards seem to be the key. That way, all-encompassing agreements for the usage of geodata should be possible, and teachers do not have to be afraid of doing something wrong regarding usage rights, for example, or they can be sure that the effort they put into preparing GI work in the classroom is sustainable and that they and their teaching can profit from it for a long period of time.

\section{Literature}

BAKER, T. R. (2002), The effects of Geographic Information System (GIS) technologies on students'attitudes, self-efficacy, and achievement in middle school science classrooms. PhD Dissertation. The University of Kansas: School of Education. 
Bohnsack, R. (2004), Group Discussion and Focus Groups. In: FLICK, U., KARDOFF, E. V. \& STEINKE, I. (Eds.), A Companion to Qualitative Research, 214-221.

Bos, W. \& TARNAI, B. (1999), Content analysis in empirical social research. International Journal of Educational Research, 31, 659-671.

DÜREN, M. \& BARTOSCHEK, T. (2013), Assessing the Usability of WebGIS for Schools. In: Jekel, T., Car, A., Strobl, J., Griesebner, G. (Eds.), GI-Forum 2013 - Creating the GISociety. Conference Proceedings. Berlin/Offenbach, Wichmann, 388-398.

FAVIER, T. \& VAN DER SCHEE, J. (2009a), Learning to Think Geographically by Working with GIS. In: JeKel, T., Koller, A., DONERT, K. \& Vogler, R. (Eds.), Learning with Geoinformation IV, Heidelberg, Wichmann, 135-145.

FAVIER, T. \& VAN DER SCHEE, J. (2009b), Learning geography by combining fieldwork with GIS. International Research in Geographical and Environ. Edu., 18 (4), 261-274.

HöHnle, S., Schubert, J. C. \& Uphues, R. (2011), Barriers to GI(S) Use in Schools. A Comparison of International Empirical Results. In: Jekel, T., Koller, A., DONERT, K. \& VoGLER, R. (Eds.), Learning with Geoinformation V. Berlin/Offenbach, Wichmann, 124-134.

Höhnle, S., Schubert, J. C. \& Uphues, R. (2010), The Frequency of GI(S) Use in the Geography Classroom. Results of an Empirical Study in German Secondary Schools. In: Jekel, T., Koller, A., Donert, K. \& Vogler, R. (Eds.), Learning with Geoinformation V. Berlin/Offenbach, Wichmann, 148-158.

Kowal, S. \& O’CONNELl, D. C. (2004), The Transcription of Conversations. In: Flick, U., KARdoff, E. V. \& SteInKE, I. (Eds.), A Companion to Qualitative Research, 248-252.

MAYring, P. (2004), Qualitative Content Analysis. In: Flick, U., KardofF, E. V. \& STEINKE, I. (Eds.), A Companion to Qualitative Research, 266-269.

MAYRING, P. (2000), Qualitative Content Analysis. In: Forum Qualitative Sozialforschung / Forum: Qualitative Social Research, http:/www.qualitativeresearch.net/index.php/fqs/article/view/1089/2385 (20 Jan. 2014).

MAYRING, P. (2007), On Generalization in Qualitatively Oriented Research [23 paragraphs]. Forum Qualitative Sozialforschung / Forum: Qualitative Social Research, 8 (3), Art. 26. http://nbnresolving.de/urn:nbn:de:0114-fqs0703262 (20 Jan. 2014).

Schubert, J. C., HöHnLE, S. \& UphueS, R. (2012), Which chances do teachers see in GI(S) usage in the classroom? Selected results from a survey of geography teachers in Germany. In: JeKel, T., CAR, A., Strobl, J. \& GriesebneR, G. (Eds.), GI_Forum 2012: Geovizualisation, Society and Learning. Berlin/Offenbach, Wichmann, 283-291.

Vogler, R., Ahamer, G. \& JeKel, T. (2010), GEOKOM-PEP - Pupil Led Research into the Effects of Geovisualization. In: JeKel, T., Koller, A., DONERT, K. \& VoGLer, R. (Eds.), Learning with Geoinformation V. Berlin/Offenbach, Wichmann, 51-60.

Zeitler, S., Heller, N. \& AsBrand, B. (2012), Bildungsstandards in der Schule. Eine rekonstruktive Studie zur Implementierung der Bildungsstandards. Münster. 